\title{
ESTUDO DAS VARIÁVEIS DE PROCESSO SOBRE A CINÉTICA DE DESIDRATAÇÃo OSMÓTICA DE MELÃO'
}

\author{
Andréa da Silva LIMA², Raimundo W. de FIGUEIREDO ${ }^{3, *}$, Geraldo A. MAIA ${ }^{3}$, Janice R. LIMA4,
}

\author{
Manoel A. de SOUZA NETO ${ }^{4}$, Arthur C. R. de SOUZA ${ }^{4}$
}

\section{RESUMO}

A desidratação osmótica representa uma alternativa tecnológica à redução das perdas pós-colheita de frutos. O presente trabalho visou avaliar a influência da concentração da solução osmótica, da proporção fruto:solução osmótica e da pressão do sistema sobre a cinética de desidratação osmótica de melão. Foram utilizadas soluções de sacarose a $45^{\circ}, 55^{\circ}$ e $65^{\circ} \mathrm{Brix}$ a $65^{\circ} \mathrm{C}$, nas proporções fruto:solução osmótica 1:2 e 1:4. Os tratamentos osmóticos foram desenvolvidos sob pressão atmosférica e vácuo, por cinco horas. A utilização de vácuo na desidratação osmótica de melão intensificou os fluxos de transporte de massa no sistema quando comparados aos dos processos sob pressão atmosférica, nas mesmas condições de concentração e proporção fruto:solução osmótica. O tratamento osmótico a vácuo, em que utilizou-se solução de sacarose a $65^{\circ}$ Brix e proporção fruto:solução osmótica 1:4, mostrou-se eficiente por acelerar a perda de água do produto, possibilitando alcançar em um curto período de tempo um alto grau de desidratação com um ganho de sólidos relativamente pequeno, quando comparado aos demais tratamentos estudados. A cinética de desidratação osmótica de melão é influenciada pelas condições de processo, notadamente pela pressão do sistema e concentração da solução osmótica.

Palavras-chave: Cucumis melo L.; pré-tratamento; processamento; pressão reduzida.

\section{SUMMARY}

STUDY OF PROCESS VARIABLES ON THE KINETICS OF THE OSMOTIC DEHYDRATION OF MELON. Osmotic dehydration represents a technological alternative to reduce post-harvest losses of fruits. The purpose of this work was to evaluate the influence of the osmotic solution concentration, fruit to osmotic solution ratio and system pressure on kinetics of the osmotic dehydration of melon. It was used $45^{\circ}, 55^{\circ}$ and $65^{\circ}$ Brix sucrose solutions at $65^{\circ} \mathrm{C}$, and $1: 2$ and $1: 4$ fruit to osmotic solution ratios. The osmotic treatments were carried out under atmospheric pressure and vacuum, for five hours. The use of vacuum in the osmotic dehydration of melon intensified the mass transport flows in the system when compared with the ones under atmospheric pressure, in the same conditions of concentration and fruit to osmotic solution ratio. The osmotic treatment under vacuum, which used $65^{\circ}$ Brix sucrose solution and $1: 4$ fruit to osmotic solution ratio, showed be efficient for speeding up the water loss of the product, making possible to reach high degree of dehydration with a relatively small solids gain, in a shorter period of time when compared with the others treatments studied. The kinetics of the osmotic dehydration of melon is influenced by the process conditions, specially by the system pressure and osmotic solution concentration.

Keywords: Cucumis melo L.; pre-treatment; processing; reduced pressure.

\section{1 - INTRODUÇÃO}

Na maioria dos países tropicais em desenvolvimento, a abundância natural de frutas frescas leva freqüentemente a um excedente de produção. Apenas uma quantidade limitada de produtos destes frutos é comercializada [8]. O melão, apesar de ser considerado um produto de elevado valor comercial e ser apreciado por suas características sensoriais, apresenta uma vidaútil pós-colheita relativamente curta à temperatura ambiente, o que tem dificultado consideravelmente a sua comercialização nos mercados mais distantes dos centros de produção, contribuindo, desse modo, para o elevado índice de desperdício desse fruto [1].

Como alternativa tecnológica à redução das perdas pós-colheita, a desidratação osmótica de frutos vem des-

\footnotetext{
1. Recebido para publicação em 23/06/2003. Aceito para publicação em 12/05/2004 (001155).

2. Parte da Dissertação de Mestrado apresentada ao Departamento de Tecnologia de Alimentos/UFC e Financiada com recursos do Banco do Nordeste-BNB. E-mail: andreadasilvalima@yahoo.com.br

3. Depto. de Tecnologia de Alimentos/UFC-Cx Postal 12168, CEP: 60356 OOO, Fortaleza-CE. E-mail: frutos@ufc.br

4. EMBRAPA Agroindústria Tropical - R. Dra. Sara Mesquita, 2270 - Planalto Pici-CEP: 60511-110, Fortaleza-Ceará.E-mail:janice@cnpat.embrapa.br; arthur@cnpat.embrapa.br

* A quem a correspondência deve ser enviada.
}

pertando grande interesse como pré-tratamento para secagem, devido ao seu baixo custo energético frente a outros métodos de desidratação, além de adequar-se a todas as escalas de produção [17]. A técnica consiste na imersão do alimento sólido, inteiro ou em pedaços, em soluções aquosas concentradas de açúcares ou sais, levando a dois fluxos de massa simultâneos: um fluxo de água do alimento para a solução e uma transferência simultânea de soluto da solução para o alimento [19]. A pressão operacional é um fator importante na cinética de transferência de massa durante a desidratação osmótica de alimentos. Portanto, tem-se estudado a aplicação de vácuo na desidratação osmótica de várias frutas, podendo esta técnica manifestar algumas características que poderiam conduzir a vantagens importantes em sua aplicação industrial, quando comparada a desidratação osmótica sob pressão atmosférica. Entre as vantagens está o aumento das taxas de perda de água pelo fruto permitindo atingir um alto grau de desidratação, e a aceleração da difusão de água do alimento que conseqüentemente reduz o tempo total de processo [7,16]. Segundo SHI \& FITO [15], o fato de manter a duração da desidratação osmótica a mais curta possivel, contribui para a obtenção de frutas desidratadas de boa qualidade.

O presente trabalho visou avaliar a influência da concentração da solução osmótica, da proporção 
fruto:solução osmótica e da pressão do sistema sobre a cinética de desidratação osmótica de melão.

\section{2 - MATERIAL E MÉTODOS}

\section{1 - Matéria-prima}

No desenvolvimento do trabalho foram utilizados melões (Cucumis melo L. c.v. Cantaloupe) adquiridos no período de janeiro a maio de 2002 em mercado varejista de Fortaleza-CE, vindos da CEASA, em estádio comercial de maturação. Em cada experimento realizado, num total de 12 tratamentos, foram utilizados $15 \mathrm{Kg}$ de polpa de melão.

Para preparação das soluções osmóticas foi utilizado açúcar cristalizado granulado, adquirido em mercado local. Os conservantes químicos adicionados à solução osmótica foram: ácido cítrico de grau alimentício (monohidratado), fabricado pela FERMENTA LTDA/SP, para corrigir o $\mathrm{pH}$, e benzoato de sódio de grau alimentício (98\%), fabricado por LIQUID QUÍMICA S.A. - Liquid Carbonic, para a estabilização do produto final. As soluções de sacarose foram preparadas adicionando-se açúcar à água (até atingir o teor de sólidos solúveis desejados), sob aquecimento para facilitar a dissolução. Em seguida, foram adicionados ácido cítrico (quantidade necessária para se atingir $\mathrm{pH} 3,0$ ) e benzoato de sódio (concentração de 0,1\%).

\section{2 - Procedimento experimental durante os trata- mentos osmóticos}

Os frutos foram recebidos na planta piloto, lavados em água clorada (50ppm de cloro ativo/15min), descascados e cortados manualmente em cubos (aproximadamente $3 \mathrm{~cm}$ ) e branqueados em vapor saturado fluente $\left(100^{\circ} \mathrm{C} / 2 \mathrm{~min}\right)$. Foram, então, imersos em soluções de sacarose $\left(45^{\circ}, 55^{\circ}\right.$ e $65^{\circ}$ Brix $)$, nas proporções fruto:solução 1:2 e 1:4, sob pressão atmosférica (760mmHg) e vácuo (660mmHg), e mantidos sob osmose à temperatura de $65^{\circ} \mathrm{C}$ por 5 h. Os experimentos de desidratação osmótica foram realizados em um tacho em aço inoxidável, com camisa de aquecimento por resistência elétrica, e sistema de vácuo por bomba d'água.

\section{3 - Determinações analíticas}

Para avaliação dos processos osmóticos foram retiradas amostras de melão em triplicata (10 cubos por amostra) no início e a cada hora de desidratação osmótica, e realizaram-se as seguintes determinações: 1- atividade de água (Aqualab CX-2- Decagon); 2- umidade [2]; 3- sólidos solúveis (refratômetro de bancada ABBE).

Para o acompanhamento da perda de peso do produto durante o tratamento osmótico, uma pequena quantidade de amostra de melão foi posta em 3 sacos telados de polietileno (contendo 10 cubos cada) devidamente identificados, os quais foram retirados da solução osmótica a cada intervalo de uma hora e, pesados em balança digital Denver Instrument-XP-1500. Após a pesagem, os sacos de polietileno retornaram ao processo osmótico. Os valores obtidos nas determinações analíticas foram utilizados para calcular os percentuais de perda de água, ganho de sólidos e perda de peso pelo fruto conforme as equações citadas por SACCHETTI, GIANOTTI \& DALLA ROSA [13].

Perda percentual de água (com base na massa inicial do material), definida por:

$$
\mathrm{P}_{\mathrm{A}}(\%)=\frac{(\mathrm{Po} \times \mathrm{Uo})-(\mathrm{Pt} \times \mathrm{Ut})}{\mathrm{Po}}
$$

Ganho percentual de sólidos (com base na massa inicial do material):

$$
\mathrm{G}_{\mathrm{S}}(\%)=\frac{(\mathrm{Pt} \times \mathrm{Bt})-(\mathrm{Po} \times \mathrm{Bo})}{\text { Po }}
$$

Perda percentual de peso:

$$
\mathrm{P}_{\mathrm{P}}(\%)=\frac{\mathrm{Po}-\mathrm{Pt}}{\mathrm{Po}} \times 100
$$

Onde:

$\mathrm{P}_{\mathrm{A}}(\%)$ - Perda de água, em \% (p/p)

$\mathrm{G}_{\mathrm{S}}(\%)-$ Ganho de sólidos, em \% (p/p)

$\mathrm{P}_{\mathrm{P}}(\%)$ - Perda de peso, em \% (p/p)

Po - Peso do fruto no tempo $t=0$, em gramas

Pt - Peso do fruto tratado no tempo $t$, em gramas

Bo $\quad-{ }^{\circ}$ Brix do fruto no tempo $t=0$

$\mathrm{Bt} \quad-{ }^{\circ}$ Brix do fruto tratado no tempo $\mathrm{t}$

Uo - Umidade do fruto no tempo $\mathrm{t}=0$

Ut - Umidade do fruto tratado no tempo $\mathrm{t}$

\section{3 - RESULTADOS E DISCUSSÃo}

\section{1 - Avaliação dos tratamentos osmóticos a pres- são atmosférica}

Nas Figuras 1 a 3 encontram-se as curvas obtidas no transporte de massa durante os experimentos para avaliação da desidratação osmótica de melão a pressão atmosférica, em relação aos parâmetros de perda de água, ganho de sólidos e perda de peso, respectivamente.

Nas Figuras 1 e 2, observa-se que, de um modo geral, as velocidades de perda de água e ganho de sólidos foram maiores nas primeiras horas de desidratação. Após este período, esses fluxos de massa tenderam a diminuir consideravelmente até que o equilíbrio fosse estabelecido no sistema (fruto:solução osmótica). Este equilíbrio se deu em torno de 4 horas de osmose, a partir do qual não foram observadas alterações significativas dos valores de perda de água e ganho de sólidos. Este comportamento está de acordo com o que foi observado por ASKAR et al. [3], PALOU et al. [10] e 
PANAGIOTOU, KARATHANOS \& MAROULIS [11], os quais estudaram a cinética de desidratação osmótica sob pressão atmosférica de diversas frutas, tais como mamão, pessêgo, maçã, banana e Kiwi.

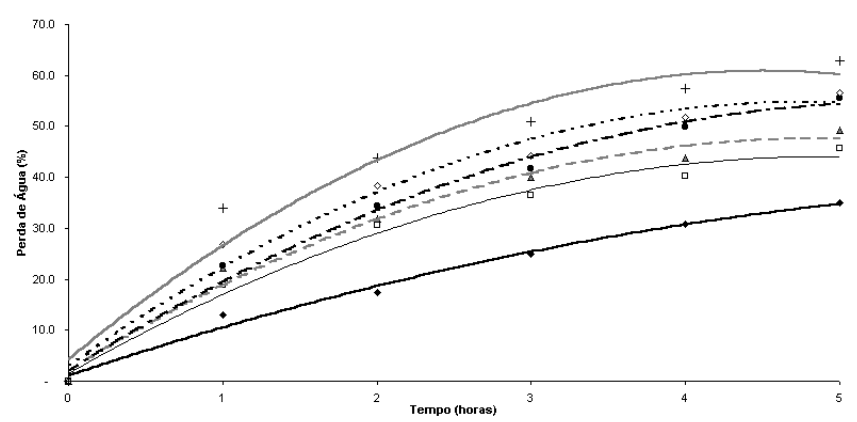

FIGURA 1. Efeito da concentração da solução e da proporção fruto:solução osmótica sobre a perda de água durante a desidratação osmótica de melão a pressão atmosférica, em solução de sacarose nas concentrações de $45^{\circ}$ (一), $55^{\circ}(-)$ e $65^{\circ}(-\cdots)$ Brix na proporção $1: 2$ e $45^{\circ}(-), 55^{\circ}$ $(\cdots)$ e $65^{\circ}(-)$ Brix na proporção $1: 4$.

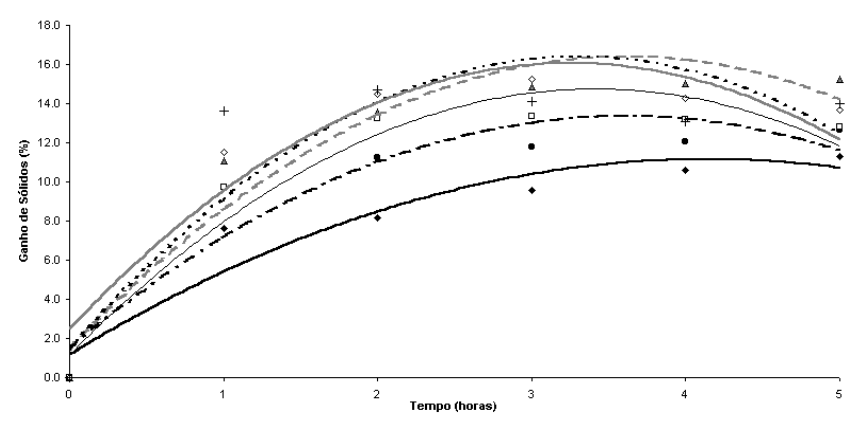

FIGURA 2. Efeito da concentração da solução e da proporção fruto:solução osmótica sobre o ganho de sólidos durante a desidratação osmótica de melão a pressão atmosférica, em solução de sacarose nas concentrações de $45^{\circ}$ (一), $55^{\circ}(--)$ e $65^{\circ}(-\cdots)$ Brix na proporção $1: 2$ e $45^{\circ}(-), 55^{\circ}$ $(\cdots$.$) e 65^{\circ}(-)$ Brix na proporção $1: 4$.

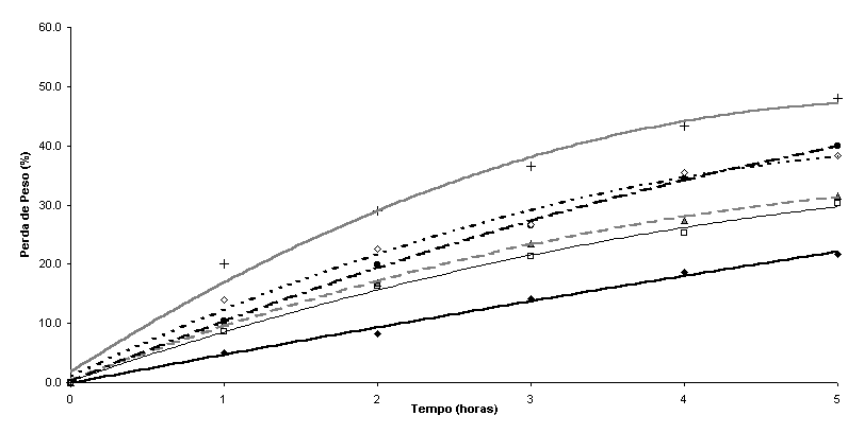

FIGURA 3. Efeito da concentração da solução e da proporção fruto:solução osmótica sobre a perda de peso durante a desidratação osmótica de melão a pressão atmosférica, em solução de sacarose nas concentrações de $45^{\circ}$ (一), $55^{\circ}(--)$ e $65^{\circ}(-\cdots)$ Brix na proporção $1: 2$ e $45^{\circ}(-), 55^{\circ}$ $(\cdots .$.$) e 65^{\circ}(-)$ Brix na proporção $1: 4$.
Na Figura 1 nota-se que o aumento da concentração da solução promoveu um aumento na taxa de perda de água durante o processo, devido ao aumento na pressão osmótica no exterior da fruta, conforme foi relatado por MIZRAHI, EICHLER \& RAMON [9]. Além disso, a utilização de maiores proporções de solução osmótica também afetou pronunciadamente a perda de água, visto que em todos os tratamentos, para uma mesma concentração da solução, houve um aumento considerável na taxa de perda de água. Segundo DALLA ROSA \& GIROUX [6], esses fluxos de massa que ocorrem durante o processo, levam a uma variação da concentração das soluções e à diminuição dos gradientes de concentração entre fruta e solução osmótica ao longo do processo. Portanto, a utilização de maiores proporções de solução osmótica minimizam o efeito da diluição da solução aumentando a eficiência da desidratação.

Na desidratação osmótica, a perda de água é acompanhada por uma incorporação de sólidos, como conseqüência das trocas difusionais que ocorrem durante o processo. Portanto, o uso de soluções mais concentradas não só promoveram aumentos na taxa de perda de água, mas também acarretaram aumentos na taxa de incorporação de sólidos (Figuras 1 e 2). SANKAT, CASTAIGNNE \& MAHARAJ [14] observaram durante a desidratação osmótica de banana à pressão atmosférica, em soluções de sacarose de diferentes concentrações, que a perda de água e o ganho de sólidos aumentaram com o aumento da concentração da solução osmótica.

Na Figura 3, verifica-se que há um aumento na perda de peso no decorrer do processo porém, visualiza-se uma tendência à estabilização ao longo do tempo, provavelmente devido ao equilíbrio atingido entre o sistema (fruto:solução osmótica). Este comportamento da perda de peso do produto tem sido relatado por vários pesquisadores $[3,12,20]$. Observa-se ainda que o aumento na concentração da solução e o uso de maiores proporções de solução osmótica levaram a uma maior perda de peso do fruto, o que pode ser explicado pelo conseqüente aumento da perda de água. Segundo SOUZA NETO [18], a predominância da taxa de perda de água em relação à de ganho de sólidos durante todo o processo osmótico explica a razão do balanço de massa negativo em todos os tratamentos, registrado pela perda de peso. Observações semelhantes também foram reportadas por BERISTAIN et al. [4] na desidratação osmótica de abacaxi. Segundo estes autores, este fato provavelmente ocorreu devido à dificuldade de difusão da sacarose através da parede celular em virtude do seu elevado peso molecular, ao contrário das moléculas de água, que tem sua difusão favorecida.

\section{2 - Avaliação dos tratamentos osmóticos a vácuo}

Nas Figuras 4 a 6 encontram-se as curvas obtidas no transporte de massa durante os experimentos para avaliação da desidratação osmótica de melão a vácuo, em relação aos parâmetros de perda de água, ganho de sólidos e perda de peso, respectivamente. 


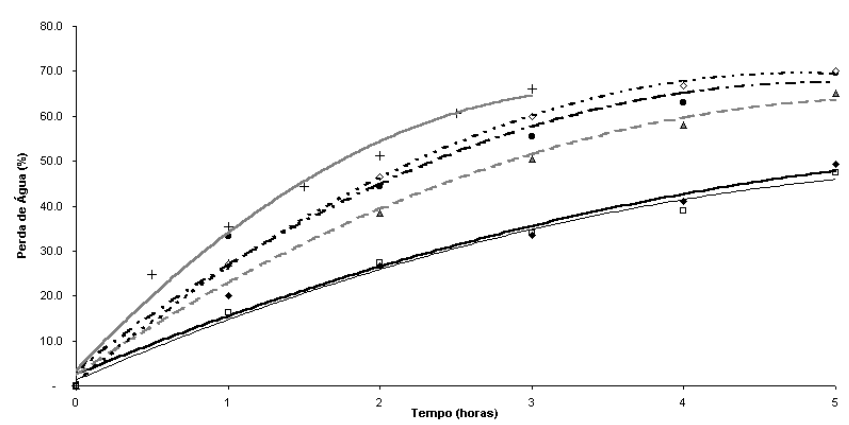

FIGURA 4. Efeito da concentração da solução e da proporção fruto:solução osmótica sobre a perda de água durante a desidratação osmótica de melão a vácuo, em solução de sacarose nas concentrações de $45^{\circ}(-), 55^{\circ}(--)$ e $65^{\circ}(-\cdots)$ Brix na proporção $1: 2$ e $45^{\circ}(-), 55^{\circ}(\cdots)$ e $65^{\circ}$ (-) Brix na proporção $1: 4$.

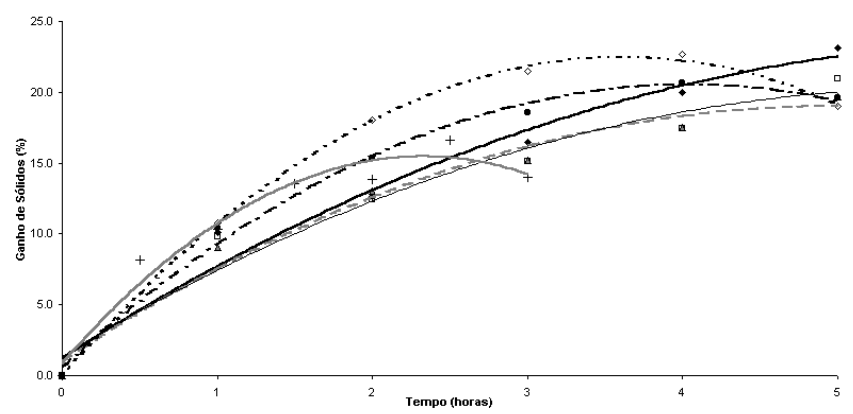

FIGURA 5. Efeito da concentração da solução e da proporção fruto:solução osmótica sobre o ganho de sólidos durante a desidratação osmótica de melão a vácuo, em solução de sacarose nas concentrações de $45^{\circ}(-), 55^{\circ}$ (- -) e $65^{\circ}(-\cdots)$ Brix na proporção $1: 2$ e $45^{\circ}(-), 55^{\circ}(\cdots)$ e $65^{\circ}$ (一) Brix na proporção 1:4.

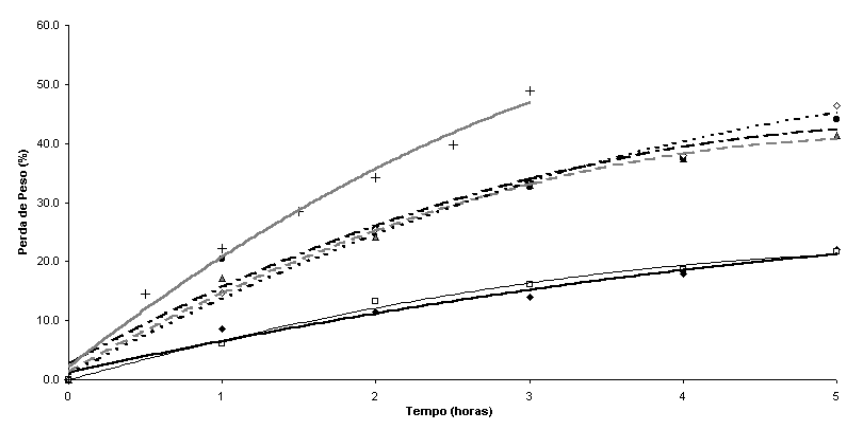

FIGURA 6. Efeito da concentração da solução e da proporção fruto:solução osmótica sobre a perda de peso durante a desidratação osmótica de melão a vácuo, em solução de sacarose nas concentrações de $45^{\circ}$ (-), $55^{\circ}$ (- -) e $65^{\circ}(-\cdots)$ Brix na proporção $1: 2$ e $45^{\circ}(-), 55^{\circ}(\cdots)$ e $65^{\circ}$ (一) Brix na proporção 1:4.

Os tratamentos realizados sob vácuo foram avaliados por um período de 5 horas, com exceção do tratamento em que utilizou-se solução osmótica a $65^{\circ}$ Brix e proporção fruto:solução 1:4, que foi concluído em 3 horas de osmose, devido à cristalização da solução osmó- tica. SOUZA NETO [18] observou, durante a desidratação osmótica a vácuo de manga, que a utilização de vácuo na temperatura de trabalho de $65^{\circ} \mathrm{C}$ promove a concentração da solução devido à evaporação de parte da água da solução osmótica no decorrer do processo, com conseqüente cristalização do açúcar contido na solução, impossibilitando assim a continuação da desidratação osmótica até o período preestabelecido.

Nas Figuras 4 e 5, observa-se que a utilização de vácuo na desidratação osmótica do melão intensificou os fluxos de transporte de massa (perda de água e ganho de sólidos) no sistema quando comparados aos da desidratação osmótica sob pressão atmosférica, nas mesmas condições de concentração e proporção fruto:solução osmótica (Figura 1 e 2). Segundo CHIRALT \& FITO [5], a utilização do vácuo permite o aumento da interface sólido/líquido devido à ocupação dos poros da matriz sólida (fruto) pela solução osmótica, o que explicaria uma maior remoção de água do fruto e um maior ganho de sólidos durante o processo osmótico.

Conforme a Figura 4, observa-se que o tratamento a vácuo em que utilizou-se solução de sacarose a $65^{\circ}$ Brix e proporção fruto:solução 1:4 apresentou em menos tempo de processo, uma taxa de perda de água similar às obtidas no processo osmótico a pressão atmosférica (Figura 1). A intensificação da perda de água pelo aumento da concentração da solução osmótica e pela aplicação de vácuo durante o processo osmótico tem sido relatado por SOUZA NETO [18] durante a desidratação osmótica de manga à pressão atmosférica e a vácuo. SHI, FITO \& CHIRALT [16] observaram em estudos realizados com damasco, morango e abacaxi que a utilização de vácuo durante a desidratação osmótica contribui para acelerar a perda de água em comparação com o tratamento a pressão atmosférica, tornando o processo mais rápido e possibilitando a obtenção de frutos desidratados de boa qualidade.

Na desidratação osmótica a vácuo, a perda de água também foi maior do que o ganho de sólidos, o que levou globalmente a uma perda de peso do produto ( $\mathrm{Fi}$ gura 6). Resultados semelhantes foram vistos por SHI \& FITO [15] e SOUSA [17] na desidratação osmótica a vácuo de abacaxi e banana, respectivamente.

De um modo geral, os tratamentos que atingiram maiores níveis de perda de água foram os tratamentos em que utilizaram soluções de sacarose mais concentradas, ou seja, $55^{\circ}$ e $65^{\circ}$ Brix, tanto nas proporções fruto:solução osmótica de 1:2 quanto de 1:4 (Figura 4). Contudo, o tratamento a vácuo em que utilizou-se solução osmótica a $65^{\circ}$ Brix e proporção 1:4, mostrou-se mais eficiente por acelerar a perda de água do produto, possibilitando alcançar em um curto período de tempo um alto grau de desidratação com um ganho de sólidos relativamente pequeno, quando comparado aos demais tratamentos estudados. Segundo TORREGGIANI [19], deve-se favorecer a perda de água com o mínimo possível de ganho de sólidos, visto que a impregnação de solutos ao alimento pode modificar as propriedades sensoriais e nutricionais dos produtos. 


\section{4 - CONCLUSÕES}

A cinética de desidratação osmótica de melão é grandemente influenciada pelas condições de processo, notadamente pela pressão do sistema e concentração da solução osmótica.

A desidratação osmótica como pré-tratamento a outros processos de preservação, como a secagem ar quente, microondas e liofilização, pode ser uma boa alternativa para a redução do teor de água presente no alimento a ser preservado, podendo reduzir o tempo total de processamento e, portanto, possibilitar a obtenção de produtos de melhor qualidade.

\section{5 - REFERÊNCIAS BIBLIOGRÁFICAS}

[1] ALMEIDA, A. S. Conservação de melão Cantaloupe "HyMark" tratado com 1-MCP após a colheita. Mossoró, 2002. 143p. Dissertação (Mestre em Fitotecnia) - Escola Superior de Agricultura de Mossoró - ESAM.

[2] AOAC. (Association of Official Analytical Chemistry) Official Methods of Analysis of the Association of Official Analytical Chemistry. 12.ed. Washington: A.O.A.C., 1992. 1115 p.

[3] ASKAR, A.; ABDEL-FADEEL, M. G.; GHONAIM, S. M.; ABDEL-GAID, I.O.; ALI, A. M. Osmotic and solar dehydration of peach fruits. Fruit Processing, v. 9, n. 1, p. 258-262, 1996.

[4] BERISTAIN, C. I.; AZUARA, E.; CORTÉS, R.; GARCIA, H. $\mathrm{S}$. Mass transfer during osmotic dehydration of pineapple rings. International Journal of Food Science and Technology, v. 25, n. 5, p. 576-582, 1990.

[5] CHIRALT, A.; FITO, P. Salting of manchego-type cheese by vacuum impregnation. In: FITO, P.; ORTEGARODRIGUEZ, E.; BARBOSA-CANOVAS, G.V editors. Food Engineering 2000. New York: Chapman \& Hall, 1996. p. 215-230.

[6] DALLA ROSA, M.; GIROUX, F. Osmotic treatments and problems related to the solution management. Journal of Food Engineering, v. 49, n. 2, p. 223-236, 2001.

[7] FITO, P. Modeling of vacuum osmotic dehydration of food. Journal of Food Engineering, v. 22, n. 2, p. 313-328, 1994.

[8] HENG, K.; GUILBERT, S.; CUQ, J. L. Osmotic dehydration of papaya: influence of process variables on the product quality. Sciences des Aliments, v. 10, n. 4, p. 831-847, 1990.

[9] MIZRAHI, S.; EICHLER, S.; RAMON, O. Osmotic dehydration phenomena in gel systems. Journal of Food Engineering, v. 49, n. 1, p. 87-96, 2001.
[10] PALOU, E.; LÓPEZ-MALO, A.; ARGAIZ, A.; WELTI, J. Osmotic dehydration of papaya: effect of syrup concentration. Revista Española de Ciencia e Tecnologia de Alimento, v. 33, n. 6, p. 621-630, 1993.

[11] PANAGIOTOU, N. M.; KARATHANOS, V. T.; MAROULIS, Z. B. Effect of osmotic agent on osmotic dehydration of fruits. Drying Technology, v. 17, n. 1/2, p. 175-189, 1999.

[12] RAOULT-WACK, A. L. Recent advances in the osmotic dehydration of foods. Trends in Food Science and Technology, v. 5, n. 8, p. 255-260, 1994.

[13] SACCHETTI, G.; GIANOTTI, A.; DALla ROSA, M. Sucrose-salt combined effects on mass transfer kinetics and product acceptability. Journal of Food Engineering, v. 49, n. 2, p. 163-173, 2001.

[14] SANKAT, C. K.; CASTAIGNNE, F.; MAHARAJ, R. Banana dehydration: osmotic, air and solar effects. In: MUJUMDAR, A. S. Drying'92. Great Britain: Elsevier Science, 1992. p. 1679-1688.

[15] SHI, X. Q.; FITO, P. Vacuum osmotic dehydration of fruits. Drying Technology, v. 11, n. 6, p. 445-454, 1993.

[16] SHI, X. Q.; FITO, P.; CHIRALT, A. Influence of vacuum treatment on mass transfer during osmotic dehydration of fruits. Food Research International, v. 28, n. 5, p. 445-454, 1995.

[17] SOUSA, P. H. M. Desidratação osmótica de banana com e sem vácuo com complemento de secagem em estufa de circulação de ar. Fortaleza, 2002. 90p. Dissertação (Mestre em Tecnologia de Alimentos) - Faculdade de Engenharia de Alimentos, Universidade Federal do Ceará (UFC).

[18] SOUZA NETO, M. A. Desidratação osmótica de manga Coité com e sem utilização de vácuo com complemento de secagem em estufa. Fortaleza, 2002. 65p. Dissertação (Mestre em Tecnologia de Alimentos) Faculdade de Engenharia de Alimentos, Universidade Federal do Ceará (UFC).

[19] TORREGGIANI, D. Osmotic dehydration in fruit and vegetable processing. Food Research International, v. 26, n. 1, p. 59-68, 1993.

[20] VIDEV, K.; TANCHEV, S.; SHARMA, R. C.; JOSHI, V. K. Effect of sugar syrup concentration and temperature on the rate of osmotic dehydration of apples. Journal of Food Science and Technology, v. 27, n. 5, p. 307-308, 1990.

\section{6 - AGRADECIMENTOS}

Agradecimentos à Fundação de Amparo à Pesquisa, à EMBRAPA Agroindústria Tropical e ao Banco do Nordeste pelo suporte financeiro. 